\title{
Molecular basis of immunoglobulin heavy constant G4 gene (IGHG4)-related low serum IgG4 subclasses in Down syndrome
}

\author{
Mohammed A. Jeraiby, MD.
}

\begin{abstract}

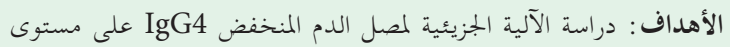

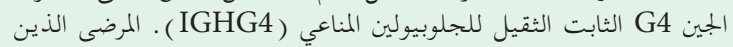

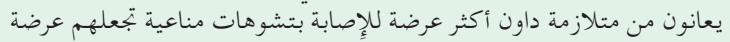

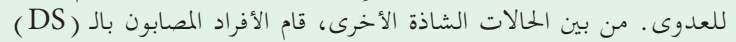

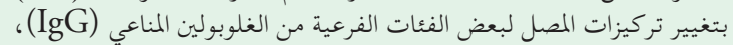
ولا سيما الفئات الفرعية IgG4.

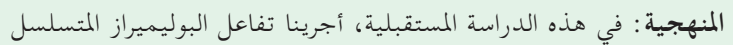

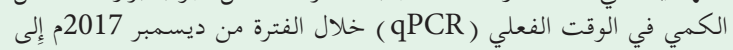

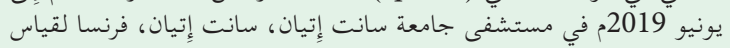

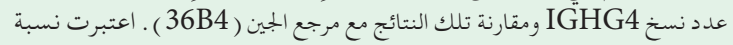
مريضًا في IGHG4/36B4

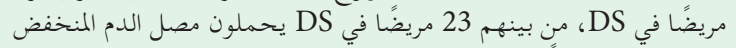

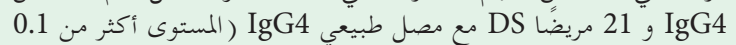

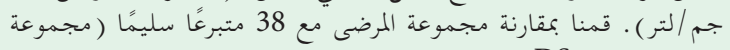

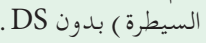

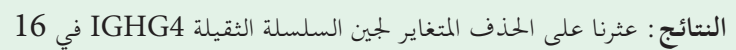

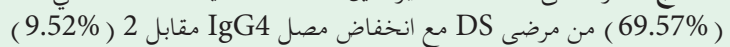

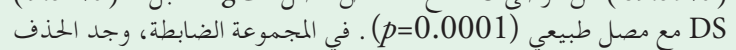
في 5.26\% (2/38 من من العينة.

الخلاصة: يرتبط جين IGHG4 المفرد ذو السلسلة الثقيلة ارتباطًا وثيقًا

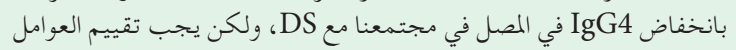

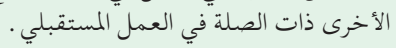

Objectives: To investigate the molecular mechanism of low serum IgG4 at the level of the immunoglobulin heavy constant G4 gene (IGHG4). Patients with Down syndrome (DS) are more likely to exhibit immunological abnormalities that predispose them to infection. Among other anomalies, individuals with DS have altered serum concentrations of some subclasses of immunoglobulin $\mathrm{G}(\mathrm{IgG})$, particularly the IgG4 subclasses.

Methods: In this prospective study, quantitative real-time polymerase chain reaction (qPCR) was carried out from December 2017 to June 2019 in the University Hospital of Saint-Etienne, Saint-Etienne, France to measure the number of IGHG4 copies and to compare those outcomes with a reference gene (36B4). An IGHG4/36B4 ratio was considered normal when between 0.8 and 1.2. Forty-four DS patients, comprising 23 DS patients carrying severe low serum IgG4 and 21 DS patients with normal serum IgG4 (level $>0.1 \mathrm{~g} / \mathrm{L}$ ). The patient group was compared with 38 healthy donors (controls) without DS.

Results: The heavy chain gene IGHG4 heterozygous deletion was found in $16(69.57 \%)$ DS patients with low serum IgG4 versus in $2(9.52 \%)$ DS with normal serum IgG4 $(p=0.0001)$. In the control group, deletion was found in $5.26 \%(2 / 38)$ of the sample.

Conclusion: The heavy chain gene IGHG4 haploinsufficiency is highly correlated with low serum IgG4 in our population with DS, but other relevant factors must be assessed in future work.

Keywords: Down syndrome, low serum immunoglobulin G4, immunoglobulin heavy chain G4 gene, $\mathrm{qPCR}$

Saudi Med J 2021; Vol. 42 (9): 975-980 doi: 10.15537/smj.2021.42.9.20210030

From the Department of Biochemistry, Faculty of Medicine, Jazan University, Jazan, Kingdom of Saudi Arabia.

Received 25th March 2021. Accepted 7th July 2021.

Address correspondence andreprintrequest to: Dr.MohammedA. Jeraiby, Biochemistry Department, Faculty of Medicine, Jazan University, Jazan, Kingdom of Saudi Arabia. E-mail: mojer2011@hotmail.com ORCID ID: https://orcid.org/0000-0002-5428-9167

$\mathrm{P}$ atients with Down syndrome (DS) are more likely to exhibit immunological abnormalities that predispose them to infection..$^{1-3}$ Among other anomalies, individuals with DS have altered serum concentrations of some subclasses of immunoglobulin G ( $\operatorname{IgG}$ ), particularly the IgG4 subclasses. ${ }^{4}$ In line with this, Anneren et $\mathrm{al}^{4}{ }^{4}$ found low serum IgG4 in $68 \%$ of DS patients. This is critical, as Loh et al, ${ }^{5}$ found that $90 \%$ 
of DS patients with severe respiratory infections had a low serum IgG4 subclass, while only $25 \%$ of healthy DS patients showed such a deficiency. However, the role of low serum IgG4 has not been fully established, as many affected persons in the general population are asymptomatic. For example, one study found that up to $15 \%$ of typically developing children and $10 \%$ of adults may have a low serum IgG4. ${ }^{6}$ In the context of DS, low serum IgG4 may be an important factor in recurrent infections, the development of autoimmune diseases, and even stroke. ${ }^{7,8}$ Despite being the lowest of all $\mathrm{IgG}$ subclasses, comprising approximately $4 \%$ of total $\mathrm{IgG}$, IgG4 may play an important role in the body's mucosal defense because of its relatively higher concentration in external secretions. ${ }^{9}$ Low levels in one or more IgG subclasses can be caused by T-cell dysfunction, deletions of the constant region of the heavy chain genes, or abnormalities of isotype switching. ${ }^{10}$ Furthermore, in vitro lymphocyte $\mathrm{T}$ and lymphocyte $\mathrm{B}$ function abnormalities are present in individuals with low IgG levels, suggesting that low IgG subclass levels may be indicative of an underlying lymphocyte $\mathrm{B}$ defect, a possible lymphocyte $\mathrm{T}$ defect, and significant immunodepression. ${ }^{11,12}$ The current literature has not provided a clear consensus on the pathogenic link between low IgG4 and the immunoglobulin heavy constant G4 gene (IGHG4) in DS.

The aim of the present study was to investigate the molecular mechanism of low serum IgG4 at the level of the heavy chain gene (IGHG4) in DS.

Methods. This prospective cross-sectional study was performed at the University Hospital of Saint-Etienne, St. Etienne, France, from December 2017 to June 2019. The inclusion criteria was all cases with DS and immunoglobulin investigation. Those who did not do an immunoglobulin investigation and did not have DS were excluded from this study.

This study included 44 patients with DS, 23 women (52.3\%) and 21 men (47.7\%) divided into 2 groups. All patients were over 7 years of age (range: 8-57 years), the age at which IgG4 reaches adult levels. ${ }^{13}$ The first group comprised patients with DS carrying severely low serum levels of IgG4 $(<0.02 \mathrm{~g} / \mathrm{L})$ and DS subjects having normal serum levels of IgG4 (level $>0.1 \mathrm{~g} / \mathrm{L}$ ), (normal range: 0.04-0.86). The patients were compared

Disclosure. Authors have no conflict of interests, and the work was not supported or funded by any drug company. to 38 healthy donors (controls) who did not have DS.

Ethical considerations were followed in agreement with the Declaration of Helsinki throughout this study, which was approved by the Research Committee of Jazan University (REC42/1/119). Consent was obtained from the patients' parents.

The IgG4 levels were analyzed in serum using Optilite (The Binding Site Group Ltd., 8 Calthorpe Road, Edgbaston, Birmingham, B15 1QT, UK) according to the manufacturer's instructions and measured in the immunology laboratory at the University Hospital of Saint-Etienne, France. A quantitative real-time polymerase chain reaction (qPCR) was carried out using the Step One Plus system (APPLIED Biosystems, Carlsbad, CA, version 2.3) to measure the number of IGHG4 copies present and compare that number to a reference gene (36B4). The process was completed in $14.5 \mu \mathrm{L}$ mixtures containing Taq polymerase, buffer solution, SYBR Green (QuantiTect SYBR ${ }^{\circledR}$ Green PCR Kits, QIAGEN), and $5 \mu \mathrm{L}$ of extracted DNA $2 \mathrm{ng} / \mu \mathrm{l}$ from whole blood samples with specific primers (IGHG4-FOR, 5' -aatcttctctctgcagagtccaaatatg-3' and IGHG4 REV,5'gttggcttacctgggcatga-3'), which were designed to amplify IGHG4 gene exon 2 . Because the structure of IGHG4 is homologous with immunoglobulin heavy constant G2 (IGHG2), we included this gene in this study using primers IGHG2-FOR, 5' -caaatgttgtgtcgagtgccca-3' and IGHG2-REV, 5'-aagactgacggtcctgccac-3' and tested other different structures in immunoglobin-like immunoglobulin heavy constant $\mathrm{E}$ using primers (IGHE) IGHE-FOR, 5'-gctgcaaaaacattccctcca-3' and IGHE REV,5'gtggtggctggtaaggtcata-3' as well. ${ }^{14}$ The reaction was performed in 2 steps, programmed for 45 cycles with primer hybridization at $60^{\circ} \mathrm{C}$. The first step consisted of using primers of a reference gene, for which the number of copies is known. The second step consisted of using the primers of the gene of interest, $I G H G 4$, for which the number of copies is desired. An $I G H G 4 / 36 B 4$ ratio was considered normal (2 copies of IGHG4) when the resulting values were between 0.8 and 1.2. To maintain the precision of the technique, electrical pipettes (Xplorer Eppendorf) were used, all DNA assays were carried out on the same day, and the same DNA dilutions were used for the 2 plates (36B4 and $I G H G 4)$.

The data was analyzed using the Statistical Package for Social Sciences (SPSS) version 22 (IBM Corp., Armonk, NY, USA). Means and standard deviations were used to express continuous variables. Categorical variables were expressed as percentages. A set of t-tests was used for continuous variables that exhibited normal 
distributions. Mann-Whitney U tests were used for nonparametric variables. The Shapiro-Wilk test was used to assess the normality of the data. A general linear model was used to assess the association between IGHG4 and B cell function, IgG, IgG1, IgG2, IgG3, IgA, and IgM. A $p$-value of $<0.05$ was considered significant.

Results. Among a total of 446 DS subjects, immunoglobin was evaluated in $53(11.9 \%)$ patients with recurrent infection. Twenty-three patients with DS (11 males and 12 females) carried severe low serum IgG4 $(<0.02 \mathrm{~g} / \mathrm{L})$, with 5 having an IgG4 level of $0 \mathrm{~g} / \mathrm{L}$ and 21 (10 males and 11 females) having normal serum levels of IgG4 (level $>0.1 \mathrm{~g} / \mathrm{L}$ ).

Among 23 patients with DS with low/undetected IgG4, 3 had congenital heart disease (13\%), 2 had otitis media $(8.7 \%)$, one had pulmonary airway malformation, 4 had hypothyroidism (17.4\%), and one had type 1 diabetes. All patients had experienced recurrent infections, mostly lower respiratory tract and ear-nose-throat infections. In the group with normal IgG4 levels, 2 suffered from hypothyroidism, one with celiac disease, and one with congenital heart malformation.

Regarding the immunoglobulin levels in the group with low/undetected IgG4 and the group with normal IgG4 serum levels, almost all patients had a normal mean ratio for the levels of $\operatorname{IgA}$, IgM, and IgG. Normal IgG subclass distribution, except that low IgG2 serum levels (IgG2 normal range: $2.4-7 \mathrm{~g} / \mathrm{l}$ ) were noted in the group with low/undetected IgG4 and normal IgG4 serum levels with mean ratios of $2.20 \pm 2.20$ and $2.24 \pm 0.85(p<0.900)$ (Table 1$)$.

In total, 82 individuals participated in screening for IGHG4 gene deletion (44 DS with and without low IgG4 levels versus 38 healthy controls). The mean ratio of IGHG4 in 23 DS patients with a low IgG4 level was $0.70 \pm 0.31$, which is significantly lower than the mean ratio of IGHG4 in the $21 \mathrm{DS}$ patients with normal IgG4 levels at $0.97 \pm 0.16,(p=0.008)$. The low serum IgG4 patients also differed from the control group (healthy subjects without DS), who had a mean ratio of $0.99 \pm 0.16, p<0.001$.

In the $23(52.3 \%)$ DS patients with low serum IgG4, $16(69.6 \%)$ had heterozygous gene deletion, while 7 (30.4\%) did not. The lowest value was 0.20 and the highest was 1.23. Among those $21(47.7 \%)$ DS patients with normal IgG4 levels, 19 (90.5\%) had no deletion, while only 2 had it $(9.5 \% ; p<0.001)$. The minimum ratio for patients with normal IgG4 was 0.52 and the maximum was 1.16 . In the control group of 38 healthy donors, only $2(5.26 \%)$ had the deletion, whereas 36 (94.7\%, $p<0.001)$ had no detectable IGHG4 deletion (Figure 1). In examining IGHG2 and IGHE among patients with $I G H G 4$ deletion, only one patient $(9.1 \%)$ presented with both an IGHG2 and an IGHE deletion (Table 2).

Table 3 shows the association between IGHG4 and B cell, IgA, and IgM total IgG and IgG sub-classes. It is clear that there is a non-significant direct relationship between IGHG4 and B cell function, IgG, IgA, and $\mathrm{IgM}$. There was a non-significant inverse relationship between IGHG4 and IgG1, IgG2, and IgG3.

Discussion. To evaluate the IGHG4 gene in DS patients with low serum IgG4, a molecular diagnosis of the IGHG4 gene revealed a deletion rate of $69.57 \%$ (16/23) among DS patients with low IgG4 levels. In contrast, Pan et al, ${ }^{15}$ reported heterozygous deletion rates for the IGHG4 gene of $1.5 \%$ in the Caucasian population and $4 \%$ in the Black population. This

Table 1 - Mean and standard deviation for B cell functions deficiency for patients with low IgG4.

\begin{tabular}{lccc}
\hline Variables & $\begin{array}{c}\text { With low/undetected } \\
\text { IgG4 level } \\
\text { Mean } \pm \text { SD }\end{array}$ & $\begin{array}{c}\text { With normal } \\
\text { IgG4 level }\end{array}$ & $P$-value \\
\hline IGHG4 & $0.53 \pm 0.17$ & $1.10 \pm 0.10$ & $<0.001^{*}$ \\
B cell (cell/uL) & $163.25 \pm 91.65$ & $199.71 \pm 67.44$ & 0.357 \\
IgG & $13.41 \pm 2.63$ & $12.41 \pm 3.72$ & 0.471 \\
IgG1 & $9.07 \pm 1.89$ & $8.36 \pm 2.72$ & 0.475 \\
IgG2 & $2.20 \pm 0.69$ & $2.24 \pm 0.85$ & 0.900 \\
IgG3 & $1.83 \pm 0.95$ & $1.20 \pm 0.84$ & 0.144 \\
IgA & $2.88 \pm 1.31$ & $2.24 \pm 1.32$ & 0.292 \\
IgM & $0.69 \pm 0.29$ & $0.67 \pm 0.36$ & 0.875 \\
\hline \multicolumn{4}{c}{ IGHG4: immunoglobulin heavy constant G4 gene, IgG: immunoglobulin G, } \\
\multicolumn{4}{c}{ SD: standard deviation } \\
\hline
\end{tabular}


IGHG4 gene deletion in down syndrome ... Jeraiby

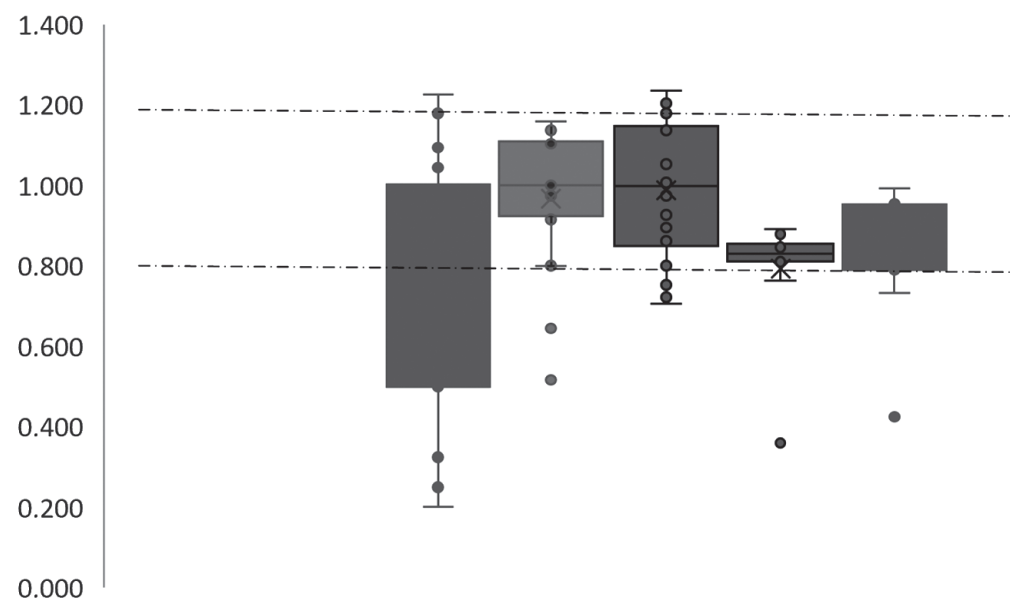

IGHG4 \IgG4 $\square$ IGHG4 N IgG4 $\square$ Healthy $\square$ IGHG2 $\square$ IGHE

Figure 1 - Comparison of immunoglobulin heavy constant G4 gene (IGHG4)/36B4 ratios: Down syndrome (DS) with low IgG4 level, DS with normal IgG4 level (N IgG4), healthy control and IGHG2/36B4 ratios, IGHE/36B4 ratios

Table 2 - Comparison of IGHG4/3664, IGHG2/3664, and IGHE/3664 for DS with Low IgG4 level.

\begin{tabular}{|c|c|c|c|c|c|c|c|}
\hline Comparison Group & $\mathrm{N}$ & Min. & Max. & Median & Mean & SD & $P$-value \\
\hline Ratio of $I G H G 4 / 36 b 4$ for DS with $\downarrow \operatorname{IgG} 4$ & 23 & 0.20 & 1.23 & 0.64 & 0.70 & 0.31 & \\
\hline Ratio of $I G H G 2 / 36 b 4$ for DS with $\downarrow \operatorname{IgG} 4$ & 11 & 0.36 & 0.89 & 0.83 & 0.79 & 0.15 & 0.167 \\
\hline Ratio of IGHE/36b4 for DS with $\downarrow \operatorname{IgG} 4$ & 11 & 0.42 & 0.99 & 0.91 & 0.85 & 0.16 & 0.149 \\
\hline
\end{tabular}

IGHG4: immunoglobulin heavy constant gamma 4

Table 3 - General linear model for the association between immunoglobulin heavy constant G4 gene (IGHG4) with B cell functions.

\begin{tabular}{lcccc}
\hline Parameter & B & \multicolumn{2}{c}{$95 \%$ confidence interval } & P-value \\
& & Lower bound & Upper bound & \\
\hline Intercept & 0.177 & -0.869 & 1.223 & 0.723 \\
B cell (cell/uL) & 0.001 & -0.001 & 0.003 & 0.294 \\
IgG & 0.127 & -0.354 & 0.609 & 0.581 \\
IgG1 & -0.103 & -0.694 & 0.487 & 0.714 \\
IgG2 & -0.104 & -0.643 & 0.436 & 0.687 \\
IgG3 & -0.261 & -0.569 & 0.047 & 0.091 \\
IgA & 0.036 & -0.089 & 0.161 & 0.547 \\
IgM & 0.203 & -0.321 & 0.728 & 0.421 \\
\hline
\end{tabular}

IgG: immunoglobulin G 
discrepancy between the present study and prior work can be attributed to differences in the techniques used by Pan et al. ${ }^{15}$ The authors used a pulsed field gel electrophoresis technique (PFGE), which provides a resolution that can identify only large deletions. In this study, I used a qPCR technique, which identifies smaller deletions. To further probe the high frequency of this deletion in this study, I studied the number of copies of the IGHG4 gene in a control group of 38 healthy people without DS, finding the deletion rate to be $5.26 \%$. This suggests that the higher rate of deletion in our study resulted from the qPCR technique.

Nevertheless, I have studied only the deletions at the level of exon 2. To specify the size of this deletion, it would be interesting to extend qPCR to other exons. Another possible technique for identification would be array comparative genomic hybridization (array $\mathrm{CGH}$ ), which has very good resolution. According to Pan et $\mathrm{al},{ }^{15}$ deletions are quite rare; thus, defects in the expression of $\mathrm{IgG}$ mainly result from poor regulation of the expression of the heavy chain gene of the constant region. However, Olsson et al, ${ }^{16}$ have identified deletions at the level of the DNA sequence of IgG1, and Zhao et $\mathrm{al},{ }^{17}$ have shown that there were mutations at the level of the DNA sequence IgG2. Moreover, additional analysis of genetic polymorphisms in individuals with low serum IgG4 levels revealed an association between decreased IgG4 levels and a minor structural defect in the IGHG4 gene. ${ }^{18,19}$ On the other hand, some data from chromosomal microarrays have also defined the potential clinical significance of the IGHG4 locus. Heterozygous deletion of IGHG4 is likely benign, according to ClinVar. ${ }^{20}$

Study limitations. There are some short comings in this study. Due to a lack of other technique, for example CGH array in our laboratory, the IGHG4 deletion in DS, need further investigation for confirmation. Therefore, I hope to improve the above mentioned issue to provide a basis for molecular investigation in DS, particularly among those with severe low/undetected serum IgG4 and who have had repeated infections.

In conclusion, patients with recurrent infection had severely low/undetected serum IgG4 levels, as well as a severely low $I G H G 4 / 36 B 4$ ratio. Because DS is a polygenic disease, the causes of low/undetected serum IgG4 in patients with DS are complex and difficult to study. These deficits could be caused by extrinsic factors linked to DS-related disturbances, which are especially important in the presence of heterozygous DS. Critically, these findings show that IGHG4 deletion is common in DS patients with low IgG4 levels. Despite the study's limitations, this finding found a genetic explanation for low/undetected IgG4 in DS patients with repeated infections. This finding may influence future recommendations for IGHG4 genetic testing in DS patients with low IgG4 levels.

Acknowledgment. The author gratefully acknowledge Dr. Touraine Renaud, Head of Génétique Clinique, Chromosomique Et Moléculaire, CHU Saint-Etienne, Saint Priez en Jarez, France for his valuable and constructive suggestions during this research work and for allowing me to use the department's instrumentation. Also, I want to thank the patients and their families for their collaboration. I would like also to thank scribendi (www.scribendi.com) for English language editing.

\section{References}

1. Burgio GR, Ugazio AG, Nespoli L, Marcioni AF, Bottelli AM, Pasquali F. Derangements of immunoglobulin levels, phytohemagglutinin responsiveness and $\mathrm{T}$ and $\mathrm{B}$ cell markers in Down's syndrome at different ages. Eur J Immunol 1975; 5: 600-603.

2. Ram G, Chinen J. Infections and immunodeficiency in Down syndrome. Clin Exp Immunol 2011; 164: 9-16.

3. Galati DF, Sullivan KD, Pham AT, Espinosa JM, Pearson CG. Trisomy 21 represses cilia formation and function. Dev Cell 2018; 46: 641-650.

4. Annerén G, Magnusson CG, Lilja G, Nordvall SL. Abnormal serum IgG subclass pattern in children with Down's syndrome. Arch Dis Child 1992; 67: 628-631.

5. Loh RK, Harth SC, Thong YH, Ferrante A. Immunoglobulin G subclass deficiency and predisposition to infection in Down's syndrome. Pediatr Infect Dis J 1990; 9: 547-551.

6. Buckley RH. Immunoglobulin G subclass deficiency: fact or fancy? Curr Allergy Asthma Rep 2002; 2: 356-360.

7. Pavone P, Falsaperla R, De Silva K, Taibi R, Verrotti A, Trifiletti $\mathrm{RR}$, et al. Down syndrome and arterial ischemic stroke in childhood: a potential immunologic link with selective IgG4 subclass deficiency. Eur J Paediatr Neurol 2014; 18: 520-525.

8. Cataldo F, Paternostro D. [ $\operatorname{IgG}$ subclasses and their clinical significance]. Minerva Pediatr 1990; 42: 509-514. Italian

9. Ogawa T, Tarkowski A, McGhee ML, Moldoveanu Z, Mestecky J, Hirsch HZ, et al. Analysis of human IgG and IgA subclass antibody-secreting cells from localized chronic inflammatory tissue. J Immunol 1989; 142: 1150-1158.

10. Teale JM, Abraham KM. The regulation of antibody class expression. Immunol Today 1987; 8: 122-126.

11. de Moraes Lui C, Oliveira LC, Diogo CL, Kirschfink M, Grumach AS. Immunoglobulin G subclass concentrations and infections in children and adolescents with severe asthma. Pediatr Allergy Immunol 2002; 13: 195-202.

12. Söderström T, Söderström R, Avanzini A, Brandtzaeg P, Karlsson G, Hanson LA. Immunoglobulin G subclass deficiencies. Int Arch Allergy Appl Immunol 1987; 82: 476-480.

13. Bayram RO, Özdemir H, Emsen A, Türk Dağı H, Artaç H. Reference ranges for serum immunoglobulin (IgG, IgA, and IgM) and IgG subclass levels in healthy children. Turk J Med Sci 2019; 49: 497-505. 
14. Brusco A, Saviozzi S, Cinque F, DeMarchi M, Boccazzi C, de Lange G, et al. Molecular characterization of immunoglobulin G4 gene isoallotypes. Eur J Immunogenet 1998; 25: 349-355.

15. Pan Q, Hammarström L. Molecular basis of IgG subclass deficiency. Immunol Rev 2000; 178: 99-110.

16. Olsson PG, Rabbani H, Hammarström L, Smith CI. Novel human immunoglobulin heavy chain constant region gene deletion haplotypes characterized by pulsed-field electrophoresis. Clin Exp Immunol 1993; 94: 84-90.

17. Zhao Y, Pan-Hammarström Q, Zhao Z, Wen S, Hammarström L. Selective IgG2 deficiency due to a point mutation causing abnormal splicing of the Cgamma2 gene. Int Immunol 2005; 17: 95-101.
18. Bottaro A, DeMarchi M, DeLange GG, Boccazzi C, Fubini L, Borra C, et al. Human IGHC locus restriction fragment length polymorphisms in IgG4 deficiency: evidence for a structural IGHC defect. Eur J Immunol 1989; 19: 2159-2162.

19. Gallina R, Bottaro A, Boccazzi C, DeLange G, Danese P, Mazzola G, et al. The genetics of IgG4 deficiency: role of the immunoglobulin heavy chain constant region and HLA loci. Eur J Immunol 1992; 22: 227-233.

20. ClinVar. National Center for Biotechnology Information [Internet]. 2014 [accessed July 11, 2021]. Available from: https://www.ncbi.nlm.nih.gov/clinvar/variation/147836/ 